\title{
Elites y cultura material en Santiago de Cali. Conexiones comerciales a través del estudio de las cartas de dote, $1750-1760$
}

\author{
Elites and material culture in Santiago de Cali. \\ Commercial connections through the study of dowry letters, 1750- \\ 1760 \\ Elites e cultura material em Santiago de Cali. \\ Conexões comerciais através do estudo de letras dote, 1750-1760 \\ David Quintero Ordóñez ${ }^{1}$ iD \\ Flacso, Ecuador
}

Para citaciones: Quintero, D. (2021). Elites y cultura material en Santiago de Cali. Conexiones comerciales a través del estudio de las cartas de dote, 1750-1760. El Taller de la Historia, 13(1), 4-24.

Recibido: diciembre 2020

Aprobado: abril 2021

Editor: Sergio Paolo Solano. Universidad de Cartagena-Colombia.
Copyright: () 2021. Quintero, D. Este es un artículo de acceso abierto, distribuido bajo los términos de la licencia https://creativecommons.org/licenses/by-nc$\mathrm{sa} / 4.0 /$ la cual permite el uso sin restricciones, distribución y reproducción en cualquier medio, siempre y cuando que el original, el autor y la fuente sean acreditados.

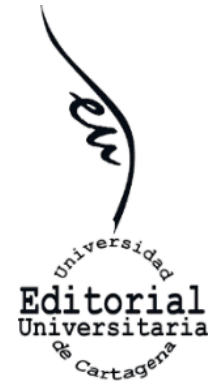

\footnotetext{
${ }^{1}$ Magíster en Estudios Latinoamericanos, especialidad en Política y Cultura, Universidad Andina Simón Bolívar. Ecuador

Doctorando en Historia de los Andes, Flacso, sede Ecuador. midaquinterofl@ flacso.edu.ec
}

Keywords: Material Life; Material Culture; Dowry; Market; Daily life.

\begin{abstract}
RESUMEN
Este texto busca exponer la vida y cultura material de las élites de Santiago de Cali en la década comprendida entre 1750-1760. A partir del análisis de las cartas de dote registradas en la Notaría Primera de la ciudad, se visibilizan las diversas redes comerciales con las que se encontraba vinculada la ciudad, y a través de las cuales, sus élites conseguían amplias posibilidades de consumo tanto utilitario como de lujo. Debido a las características de la práctica de la dote, entre ellas los exhaustivos inventarios incluidos en el protocolo notarial, es posible acceder a los elementos más básicos o aquellos de carácter personal entregados al momento de contraer matrimonio. La procedencia de textiles, piedras preciosas y otros objetos ayuda a establecer gustos, ofertas, demandas, así como la interacción entre diversas geografías dentro del mercado local.
\end{abstract}

Palabras clave: vida material; cultura material; dote; mercado; vida cotidiana. 


\section{RESUMO}

Este texto busca expor a vida e a cultura material das elites de Santiago de Cali na década entre 1750-1760. A partir da análise das cartas dotes registradas no Primeiro Tabelião da cidade, as diversas redes comerciais com as quais a cidade estava ligada são visíveis, e através das quais suas elites obtiveram amplas possibilidades de consumo tanto utilitária quanto de luxo. Devido às características da prática do dote, incluindo os inventários exaustivos incluídos no protocolo notarial, é possível acessar os elementos mais básicos ou os de natureza pessoal entregues no momento do casamento. A procedência de têxteis, pedras preciosas e outros objetos ajuda a estabelecer gostos, ofertas, demandas, bem como a interação entre diferentes geografias dentro do mercado local.

Palavras-chave: vida material; cultura material; dote; mercado; vida cotidiana.

\section{Introducción}

La dote entregada al momento de contraer nupcias jugaba un papel central dentro de las practicas matrimoniales de los grupos más acomodados de la sociedad hispanoamericana. En el caso de Santiago de Cali este sector estaba compuesto por sujetos dedicados a la minería, el comercio y la hacienda ${ }^{2}$, actividades lo suficientemente lucrativas para garantizar el acceso a mercaderías de diversa procedencia. Este texto busca establecer algunas de las conexiones comerciales de estas élites con diversas geografías, a través de la presencia en la ciudad de ciertos bienes y objetos materiales. Las prendas de vestir, los muebles, e incluso la joyería, permiten vincular el acceso y preferencia de un grupo social determinado, con la existencia de redes transatlánticas y transpacíficas de circulación, en las que se encontraba inserta la localidad.

Los estudios sobre cultura material se han posicionado como un campo capaz de aportar nuevas perspectivas sobre la vida cotidiana, ya no concentrándose solo en la oferta de ciertos bienes sino también en la demanda de ellos. Lo anterior en gran medida fomentado por cambios culturales, sociales y económicos. Los niveles de vida se encuentran estrechamente ligados al consumo doméstico, aquellos objetos de carácter duradero y con algún nivel de importancia, pueden ser rastreados a través distintos inventarios notariales ${ }^{3}$. Testamentos, ventas, mortuorias y cartas de dote, entre otros documentos, dan cuenta de los bienes circulantes dentro de la sociedad.

Los objetos nos ayudan a pensar en una historia global que ha tenido múltiples conexiones desde hace varios siglos, estableciendo intrincados circuitos, gracias a los cuales, diversas geografías se conectaron e intercambiaban

\footnotetext{
${ }^{2}$ Germán Colmenares, Cali: terratenientes, mineros y comerciantes. Siglo XVIII, Cali. Universidad del Valle, 1976. ${ }^{3}$ Bartolomé Yun, "Cultural material: consumo, niveles de vida, estilo de vida". Noticiario de Historia Agraria, 6, 1993: $139-142$
} 
objetos considerados como valiosos ${ }^{4}$. Para el siglo XVIII, el entramado comercial incluía a la mayoría de los continentes poblados, participando con los recursos disponibles 5 . La idea, en lo posible, es seguir la cadena que recorren estas 'cosas' para tener un mejor entendimiento del contexto histórico, tanto del lugar en que se producen o extraen, así como su destino ${ }^{6}$. En el caso americano, su inserción a través de la plata y otros productos en el sistema mundo le permitió insertarse dentro de estos circuitos ${ }^{7}$. ya fuese mediante los monopolios imperiales legalmente establecidos, o en circuitos basados en el contrabando.

Este articulo inicia con algunas reflexiones sobre la figura de la dote matrimonial dentro de la historiografía, principalmente en lo referente a las definiciones jurídicas y sociales de este arreglo. La segunda sección está dedicada a la vestimenta, vinculando procedencia de los textiles, tipo de prendas, decoración y materiales de confección. La tercera se concentra en las piezas de joyería, no solo como marcadores de estatus y distinción, sino como objetos que dan cuenta de amplias conexiones comerciales. Finalmente, se presentará un apartado destinado a diversos objetos de uso doméstico cuya procedencia permite ver con mayor claridad las distintas rutas mercantiles presentes en la ciudad, y la cultura del consumo presente en las élites de la época.

En cuanto a la periodización, responde principalmente a los factores económicos que se dieron durante la segunda mitad del siglo XVIII en Cali. Para ese momento la ciudad gozaba de una prosperidad minera que permitía la acumulación de caudales lo bastante grandes como para verse reflejados en los montos, la calidad y procedencia de los objetos entregados por vía de dote. Los documentos utilizados como fuentes primarias son las Cartas de recibo de Dote registradas en los libros de la Notaría Primera, más puntualmente la década comprendida entre 1750 a $1760^{8}$.

\section{La dote hispanoamericana, una aproximación a la práctica}

Los esfuerzos realizados por las familias de la novia y en muchos casos por ellas mismas para entregar una buena dote tenía varias razones; por un lado, la composición y el monto eran capaces de asegurar un buen marido y con él una alianza familiar conveniente; por otro la variedad y calidad de los elementos aportados mostraban a la sociedad el estatus y la capacidad económica, tanto de la dama como de su entorno familiar.

\footnotetext{
${ }^{4}$ Dennis O. Flynn and Arturo Giraldez, "Bom with a Silver Spoon: The Origin of World Trade in 1571", Journal of World History, 6, (2), 1995: 201-220.

${ }^{5}$ Andre Gunder Frank, Reorient, Global Economy in Asian Age, Berkeley, University of California Press, 1998.

${ }^{6}$ Camilo Quintero Toro, "Entendiendo los objetos y las mercancías en perspectiva histórica: presentación del dossier "Objetos y mercancías en la historia". Historia Critica, 38, 2009: 14.

${ }^{7}$ Carlos Marichal, "El peso de la plata hispanoamericana como moneda universal del antiguo régimen (siglo XVI a XVIII)", en Carlos Marichal, Steven Topik y Zephyr Frank (coords.), De la Plata a la Cocaína. Cinco siglos de historia económica de América Latina, 1500-2000, México, FCE/COLMEX, 2017, pp. 37-75

${ }^{8}$ Archivo Histórico de Cali (en adelante AHC). Fondo escribanos, Subfondo: Notaria Primera, Serie Dotes, Subserie: Cartas de Dote Tomos del 25 al 35, años de 1750-1760
} 
Estos objetos no solo tenían una importancia monetaria, al incluir elementos destinados a garantizar la reproducción económica de una pareja, mediante la entrega de esclavos, haciendas, ganado, herramientas entre otros, sino también de orden simbólico, sirviendo como marcadores sociales de distinción y prestigio, entre ellos las elaboradas prendas de vestir y las extravagantes piezas de joyería, mobiliario, arte religioso entre otros ${ }^{9}$.

En el Nuevo Reino de Granada, aunque también para el conjunto del Imperio Hispánico, la práctica de la dote matrimonial fue central, aunque no determinante al momento de concretar el matrimonio ${ }^{10}$. En este tipo de documentación, es posible encontrar las características socioeconómicas de las provincias del virreinato o si se quiere, de las distintas geografías imperiales ${ }^{11}$. La vocación productiva, el acceso a determinados recursos naturales y la posibilidad de acumular riquezas, se manifiestan la diversidad, procedencia y calidad de los objetos que componían la vida material de las sociedades.

Si bien la dote no era un elemento obligatorio al momento de contraer matrimonio, se la considerada como una práctica enmarcada en la tradición y de gran importancia para los sectores de elite ${ }^{12}$. Gracias a los objetos que circularon por este medio, es posible reconstruir la vida material de las élites caleñas, la meticulosidad de estos inventarios puede ser considerado como una prueba de su importancia ya que cada uno de los componentes traía consigo una carga simbólica, cultural y económica.

La dote puede ser vista como una transacción económica entre la familia de la novia y su futuro esposo, la cual, quedaba registrada ante un notario con el fin de garantizar su posterior devolución en caso de darse cualquiera de las situaciones sancionadas en diversos corpus jurídicos. Solo por mencionar algunos, en las Siete Partidas, y en la Recopilación de Leyes de Indias, quedaba claro que el marido actuaba como administrador de los capitales, no se lo consideraba como el dueño, ni tenía plena potestad para disponer de ellos, este punto, desde cualquier interpretación que pudiese hacerse, resultaba taxativo.

Desde los estudios de la jurisprudencia colonial se plantea a la dote como un sistema por medio del que las mujeres colaboran en el mantenimiento de la familia, a la vez que constituía un fondo económico que las amparaba en caso de disolución del matrimonio ${ }^{13}$. En las ya mencionadas Siete Partidas se establecía que, si la dote había sido malgastada por el marido este debía

\footnotetext{
${ }^{9}$ Aída Martínez Carreño, La prisión del vestido: Aspectos sociales del traje en América, Bogotá, Planeta, 1995.

${ }^{10}$ Jorge Gamboa, El precio de un Marido: El significado de la dote matrimonial en el Nuevo Reino de Granada. Pamplona (1550-1650), Bogotá, Instituto Colombiano de Antropología e Historia, Colección Cuadernos Coloniales, 2003, pp. 9-46

${ }^{11}$ Pablo Rodríguez, Sentimientos y vida familiar en el Nuevo Reino de Granada, Bogotá, Editorial Planeta, 1997, p. 189.

${ }^{12}$ J. Gamboa, El precio de un Marido, p. 52.

13 Ángel Rodríguez Sánchez, "Un modelo metodológico: las cartas de dote en Extremadura". Jornadas de Metodología

Histórica Aplicada. La documentación Notarial y la Historia, vol. I, Santiago de Compostela, 1984, pp. 165-176
} 
restituirla abriendo la posibilidad a la esposa de demandar en juicio ${ }^{14}$. Esta posibilidad de litigar por los capitales dotales se amparaba en al menos dos elementos.

El primero de ellos, consistía en demostrar los malos manejos de los bienes por parte de los esposos, para lo cual eran necesarios testigos, la existencia de un registro puntual de aquello entregado avalado por un escribano. En segundo lugar, para poder reclamar la restitución del patrimonio, era indispensable contar con un registro notarial minucioso de aquello que había ingresado por esta vía ${ }^{15}$.

Desde la antropología la dote ha sido vista como un medio para comprender el campo de las prestaciones matrimoniales. Preocupándose más por el análisis de las líneas de parentesco al interior de las sociedades, diversos autores han definido dos sistemas de prestaciones usando como medio de clasificación la dirección de la procedencia de los bienes. El más común es aquel en que el novio entrega una serie de elementos materiales a la familia de su esposa. En el segundo es la novia quien se encarga de entregarlos. Para desprenderse de la idea de transacción financiera, Lucy Mair plantea el uso del concepto "Fondo de la Novia"16.

Es posible afirmar que las dotes en el mundo hispánico cumplían varias funciones y debido a su importancia, estaban contempladas en diversos corpus jurídicos con el fin de proteger, distribuir y finalmente indicar la forma como se podían usar estos recursos. Socialmente, sus montos permitían a una familia hacer pública su capacidad adquisitiva y estatus, llegando a convertirse en una herramienta vital para garantizar uniones ventajosas. Económicamente la dote permite no solo conocer de primera mano las actividades desarrolladas por una familia en particular, sino también dar cuenta de lógicas mucho más amplias en las cuales se encuentran insertos los sujetos.

La protección jurídica por su parte, garantizaba que las mujeres de las elites no perdieran sus recursos a manos de esposos derrochadores. La posibilidad de litigar en caso de que existiera malversación de los fondos, les permitió en muchos casos recuperar sus bienes, evitar la pérdida de lo que quedaba e incluso, iniciar vidas completamente independientes de su lecho matrimonial. Igualmente, importante, contar con estos capitales y disponerlos libremente, garantizaba el legarlos posteriormente a sus hijas garantizando para ellas una unión marital ventajosa ${ }^{17}$.

\footnotetext{
${ }^{14}$ Las siete partidas del Rey Don Alfonso el Sabio. Disponible en: http://www.cervantesvirtual.com/obra-visor/las-sietepartidas-del-rey-don-alfonso-el-sabio-cotejadas-con-varios-codices-antiguos-por-la-real-academia-de-la-historia-tomo-3partida-quarta-quinta-sexta-y-septima--0/html/01fb8a30-82b2-11df-acc7-002185ce6064_92.htm

${ }_{15}$ Kimberly Gauderman, Women's Lives in Colonial Quito: Gender, Law and Economy in Spanish America. Austin, University of Texas Press, 2009.

${ }^{16}$ Lucy Mair, Matrimonio, Barcelona, Barral Editores, 1972.

${ }^{17} \mathrm{~K}$. Gauderman, Women's Lives in Colonial Quito.
} 


\section{El vestuario de las mujeres de la elite, procedencia, adornos y tipos de prendas}

El vestuario se presenta como uno de los mejores indicadores de la posición social ocupada por un sujeto. El dinero que se invierte en los distintos atavíos y el lujo de las prendas no deben verse únicamente como vanidad de los actores, ya que demuestran de manera tajante el éxito económico, político y social de los mismos ${ }^{18}$. También expresa el espíritu del tiempo, siendo uno de los indicios más inmediatos de cambios sociales, políticos, económicos y culturales $^{19}$. El uso de tal o cual material, la presencia de ciertas prendas, e incluso los colores pueden cobrar una gran relevancia en los momentos de transformación histórica, así como la preferencia por la procedencia de los textiles y adornos pueden dar cuenta de escases económica o auge.

Al realizar una historia del vestuario se presentan diversas variables a considerar. Por un lado, el origen de las materias primas usadas en la fabricación de los atuendos lo cual va ligado con los procedimientos de fabricación y los costos. Por otro, se encuentran las fijaciones culturales, las modas y las jerarquías sociales ${ }^{20}$. En el caso caleño, aquellas familias con la mejor posición económica y gran influencia social, buscaron estar en sintonía con la moda europea, en muchos casos trayendo las prendas o los textiles para su elaboración desde el viejo mundo. Esto principalmente desde España Francia e Inglaterra, los dos últimos como grandes productores de estas mercaderías. Junto a ellas, se utilizaron también telas provenientes de otras regiones del virreinato como Pasto, Anchicayá, Santa Fe y otros traídos de ciudades como Quito y Lima. La variedad en los materiales, procedencias y tipos de vestuario señala de manera concreta las capacidades económicas de una familia, sus gustos, así como de manera más general la demanda por determinados géneros frente a otros.

Entre 1750 y 1759 las cartas dotales registradas en la Notaría Primera, contienen valiosa información sobre el vestuario usado por las damas caleñas. De las 26 cartas dotales cuyo monto total es de 1.045 .448 patacones con 3 reales, 7.262 corresponden al valor de los 462 artículos $^{21}$. Estas prendas de vestir y varas de tela representa alrededor del $35 \%$ del valor total de la década, si bien otros elementos tienen mayor peso porcentual, queda claro que la ropa jugó un papel determinante al momento de formar una dote.

Una particularidad de las prendas entregadas por vía de dote es que un buen número de ellas eran nuevas, esto en gran medida por la mayor oferta de textiles causada por la primera Revolución Industrial, la cual permitió una

\footnotetext{
${ }^{18}$ Edgardo Pérez Morales, "Del hábitat a los hábitos. Vida material y sociedades urbanas en el Nuevo Reino de Granada, siglo XVIII", en Yobenj Aucardo Chicangana-Bayona (ed.), Historia, cultura y sociedad colonial, siglos XVI-XVIII. Temas, problemas y perspectivas, Medellín, La Carreta/Universidad Nacional de Colombia, 2008, pp. 333-362.

${ }^{19}$ Nicola Squicciarino, El vestido habla: Consideraciones psicosociológicas sobre la indumentaria, Madrid, Ediciones Cátedra, 1990.

${ }^{20}$ Fernand Braudel, Civilización material y capitalismo, Barcelona, Editorial Labor, 1974, p. 243.

${ }^{21}$ AHC, Fondo Escribanos, Subfondo: Notaria 1, Serie: Dotes, Subserie: Cartas de Dote, Tomos: 25 al 35.
} 
mayor producción y caída de los precios. En este sentido, el siglo XVIII estuvo marcado por la renovación permanente de los guardarropas siguiendo las tendencias provenientes del viejo continente, rompiendo con la adaptación de la vestimenta mediante el uso de brocados, sedas y terciopelos, propia del siglo XVII ${ }^{22}$.

Tabla 1: Prendas de vestir registradas en las Cartas Dotales 1750-1759

\begin{tabular}{lrr}
\hline \multicolumn{1}{c}{ Articulo } & \multicolumn{1}{c}{ Cantidad } & Valor en Patacones \\
\hline Ropa de Cama & 48 & 550,4 \\
\hline Calzones & 36 & 217 \\
\hline Sombreros & 18 & 224 \\
\hline Casaquetas & 17 & 680 \\
\hline Follados & 12 & 379 \\
\hline Vuelos & 9 & 70 \\
\hline Naguas & 35 & 293 \\
\hline Volantes & 12 & 151,4 \\
\hline Camisas & 86 & 594 \\
\hline Mantellinas & 18 & 1.008 \\
\hline Sayas & 29 & 1.364 \\
\hline Chupas & 8 & 122 \\
\hline Corpiños & 6 & 48 \\
\hline Varios & 128 & 1.561 \\
\hline Totales & $\mathbf{4 6 2}$ & $\mathbf{7 2 6 2}$ \\
\hline
\end{tabular}

Fuente: elaborada por el autor con base en los registros notariales de cartas de dote consignados en el AHC, Fondo escribanos, Subfondo: Notaria Primera, Serie Dotes, Subserie: Cartas de Dote Tomos del 25 al 35, años de 1750-1759.

En general las mujeres de Cali se inclinaban por el uso de sayas, camisas, mantellinas, rebosos, mantos, volantes, sombreros y enaguas presentes en la mayoría de las cartas de dote. Los adornos realizados con encajes y algunas incrustaciones de metales preciosos como el oro y la plata son también muy frecuentes en los registros, sin olvidar que las joyas servían como otro indicador y su uso era más que frecuente entre las capas altas de la sociedad, pero incluso también en algunos con una capacidad económica tan alta como lo denota el monto de su dote, mismas que en la totalidad de los casos contenía alguna pieza de joyería.

Los valores de las prendas resultan profundamente disimiles entre sí, mediante el uso oro, plata, bordados, encajes y cintas, era posible aumentar el costo al momento de valorarlas. Sin embargo, aquellas prendas más simples,

${ }^{22}$ Pilar Gonzalbo, "De la penuria y el lujo en la Nueva España: Siglos XVI-XVIII". Revista de Indias, 56, (206), 1996: 4974. 
o "llanas" permiten hacerse una idea de la posible variación en los precios. Es así como volantes, mantellinas, camisas de Bretaña, sábanas de Ruan, mantuvieron un valor constante durante la segunda década del siglo XVIII.

Sábanas, colchas, almohadas, entre otros, fueron entregadas en su mayoría nuevas, para engalanar el lecho matrimonial. Como espacio privado ligado a la feminidad, la alcoba cumplía no solo un papel práctico, sino también simbólico, controlado por la esposa y aportado por ella o su familia. No es de extrañar el uso de prendas traídas principalmente de Ruan y Bretaña para este espacio íntimo, en el cual, se debía no solo consumar el matrimonio, sino también servir como espacio de descanso.

Se dejó constancia de 47 artículos con un valor de 540 patacones con 4 reales, los cuales provenían de lugares muy lejanos como el norte de Francia principalmente de Ruan y Bretaña. Los registros hablan también de objetos confeccionados con Damasco, además de algunos guarnecidos con cintas, encajes y catatumbas. Aquellos más simples y poco valorados aparecen descritos como llanos.

Tabla 2: Artículos de Cama

\begin{tabular}{lrr}
\hline Artículo & $\begin{array}{c}\text { Cantidad de } \\
\text { Registros }\end{array}$ & $\begin{array}{c}\text { Valor en } \\
\text { Patacones }\end{array}$ \\
\hline Colcha & 2 & 94 \\
\hline Sobrecama & 4 & 120 \\
\hline Cobija & 3 & 51 \\
\hline Sábanas & 22 & 166,4 \\
\hline Fundas & 12 & 92 \\
\hline Almohadas & 4 & 17 \\
\hline Total & $\mathbf{4 7}$ & $\mathbf{5 4 0 , 4}$ \\
\hline
\end{tabular}

Fuente: elaborada por el autor con base en los registros notariales de cartas de dote consignados en el AHC, Fondo escribanos, Subfondo: Notaria Primera, Serie Dotes, Subserie: Cartas de Dote Tomos del 25 al 35, años de 1750-1759.

Es posible que el gusto por los géneros provenientes de estos lugares esté relacionado con su calidad y finura. El norte de Francia era reconocido por sus textiles de excelente calidad, los cuales sin duda alcanzaron las tierras americanas. Durante el siglo XVIII los distintos centros urbanos ubicados en esta región aumentaron la cantidad de piezas producidas, obligándolas a buscar mercados debido a la competencia representada por los textiles ingleses, de menor calidad, pero con un costo menor.

Las habitaciones y especialmente una alcoba marital, representa en si misma todo un microcosmos, en el cual, materialidad, simbología, recuerdos, y otros tantos elementos se conjugan para compartir un mismo espacio físico. En este lugar no solo se dan cita el reposo, sino tal como lo plantea M. Perrot, "el sueño, el deseo, el amor, la meditación, la lectura, la escritura, la búsqueda de 
uno mismo o de Dios, la reclusión voluntaria o forzada, la enfermedad, la muerte están presentes" 23 . La ropa de cama, al igual que los muebles destinados a estos espacios, pueden dar cuenta de procesos culturales mucho más profundos, ligados a la vida íntima de los sujetos, sus gustos, sus capacidades, e incluso, cambios estructurales en la concepción de la vida marital y la pareja.

Las camisas eran indispensables en los roperos, 4 provenían de Bretaña con un valor de 44 patacones. Estas prendas fueron registradas en la dote de Clemencia Garcés y Saa ${ }^{24}$ una aparece como "nueva" de tamaño ancho y su valor fue de 18 patacones, otra se tazó en 10 con la misma característica, pero su estado era el de usado; la última se describe como una prenda bastante usada valorada en 16 patacones. A estas se le sumaron 3 camisas fabricadas en Olan, ${ }^{25}$ el cual si bien es poco común al inicio del siglo posteriormente se hará cada vez más normal en los documentos.

Si de prendas de vestir se trata, las mantellinas o mantillas usadas para envolver la cabeza de las mujeres formaban parte de la vida cotidiana. Una dama cubierta con este accesorio podía caminar libremente por las calles y otros espacios de la ciudad sin que con ello comprometiera el buen nombre de su familia. ${ }^{26}$ El uso de estas piezas se generalizó entre las mujeres ya fuesen de la elite o de sectores populares, se puede intuir que se aseguraron de contar con varias para usarlas según la ocasión y distinguirse mediante la calidad de otras mujeres.

Algunas fueron fabricadas con seda o paños para el uso diario, otras bordadas con puntas y encajes para los días de fiesta o celebraciones religiosas. El material de confección más común fue el Terciopelo, con agregados como vueltas de encajes y puntas de algún mineral. Una mantilla "común" estaba alrededor de los 50 patacones, mientras que una finamente elaborada, llegaba a costar 135 patacones. También era común el uso de Bayeta ${ }^{27}$ junto con el Brocato $^{28}$, no es posible conocer si eran prendas de elaboración local, regional o en su defecto, provenían de otras geografías, lo que, si queda claro, es que no se escatimaban gastos en su decoración.

Uno de los implementos más utilizados por las mujeres eran las sayas, faldas bastante adornadas, confeccionadas en distintos materiales destinadas al uso cotidiano $^{29}$. Estas prendas eran claves a la hora de hacer alarde de la posición social ocupada, adornos como puntas de hilo de plata, varias vueltas de

\footnotetext{
${ }^{23}$ Michelle Perrot, Historia de las alcobas, Madrid, SIRUELA, 2011

${ }^{24}$ AHC, Fondo Escribanos, Subfondo: Notaria 1, Serie: Dotes, Subserie: Cartas de Dote, Tomo: 26, Folios: $96-99$, 21 de Marzo de 1752.

${ }^{25}$ Lienzo muy fino usado comúnmente en la fabricación de sabanas y camisas.

${ }^{26}$ Magdalena Chocano Mena, La América Colonial (1492-1763), Madrid, Ed. Síntesis, 2000, p. 74.

27 Tela de lana floja y poco tupida.

28 Tela tejida que suele en la mayoría de los casos estar ricamente decorada, casi siempre se fabricaba entrelazando sedas de colores a la cual además se le agregaban como elementos de ornamentación, hilos de oro y plata

${ }^{29}$ A. Martínez Carreño, La prisión del vestido.
} 
encajes comunes o finos, otros guarnecidos en Galón de Oro ${ }^{30}$, cumpliendo una función social además de práctica.

Las cartas contienen en total 29 de estos objetos con un valor de 1.364 patacones, los materiales de su confección son muy variados, se encuentran cuatro Sayas de Terciopelo con distintos agregados, dos de Damasco y dos de Granilla, en cuanto a los registros individuales se pueden encontrar algunas fabricadas en: Brocato $^{31}$, Tornasol, ${ }^{32}$ también algunas en Imperiosa ${ }^{33}$, y finalmente una de Fiuri ${ }^{34}$. Finalmente aparecen algunos registros de prendas confeccionadas en Pelo de Camello ${ }^{35}$.

Las casaquetas son otro elemento con un buen número de registros, esta prenda es casaquitas definida como una vestidura con mangas y faldones ceñida al cuerpo ${ }^{36}$. Normalmente acompañaba a las sayas, con el paso de los años ambas prendas se registrarán juntas hasta su desaparición terminando el siglo. El mayor número de registros en una sola carta es de 14 artículos, los cuales fueron entregados nuevamente por doña Juana Garcés y Saa ${ }^{37}$, su confección fue en Terciopelo de varios colores, con un valor total de 420 patacones en promedio.

Los sombreros eran un accesorio cuyo uso aumentó con el paso de los años, seguramente relacionado con la creciente popularidad en Europa y el aumento en su producción. En esta década se dotaron 18 piezas, repartidos en 6 de las cartas de dote con un valor de 224 patacones. Posteriormente su número fue en aumento casi hasta convertirse en un objeto infaltable al momento de vestirse terminando el siglo XVIII.

El mayor número de sombreros registrados en una carta de dote fueron entregados por doña Antonia de Castro y Zeballos ${ }^{38}$ tanto en su dote como en la mejora. En este caso, los 7 sombreros se valoraron en 74 patacones, lastimosamente no se hace referencia al material de fabricación, ni a su color, forma u otra característica.

Otro registro es el de doña María Niño hija del capitán mayor don Juan Niño ${ }^{39}$, igualmente tenemos un sombrero color blanco aportado por María Francisca

\footnotetext{
${ }^{30}$ Tejido fuerte y estrecho utilizado para guarnecer vestidos u otra ropa

${ }^{31}$ AHC, Fondo Escribanos, Subfondo: Notaria 1, Serie: Dotes, Subserie: Cartas de Dote, Tomo: 29, Folios: 192-195, 8 Junio de 1755 .

${ }^{32}$ AHC, Fondo Escribanos, Subfondo: Notaria 1, Serie: Dotes, Subserie: Cartas de Dote, Tomo: 27, Folios: 142v-147v 1 Agosto de 1753.

${ }^{33}$ AHC, Fondo Escribanos, Subfondo: Notaria 1, Serie: Dotes, Subserie: Cartas de Dote, Tomo: 31, Folios: 67v-72v, 22 de Abril de 1756.

${ }^{34}$ AHC, Fondo Escribanos, Subfondo: Notaria 1, Serie: Dotes, Subserie: Cartas de Dote, Tomo: 27, Folios: 95-99v, 7 de Julio de 1753.

${ }^{35}$ AHC, Fondo Escribanos, Subfondo: Notaria 1, Serie: Dotes, Subserie: Cartas de Dote, Tomo: 35, Folios: 263-265v, 25 de Agosto de 1759.

${ }^{36}$ A. Martínez Carreño, La prisión del vestido.

${ }^{37}$ AHC, Fondo Escribanos, Subfondo: Notaria 1, Serie: Dotes, Subserie: Cartas de Dote, Tomo: 27, Folios: 95-99v 7 de Julio de 1753.

${ }^{38}$ AHC, Fondo Escribanos, Subfondo: Notaria 1, Serie: Dotes, Subserie: Cartas de Dote, Tomo: 27, Folios: 179v-187, 25 de Agosto de 1753.

${ }^{39}$ AHC, Fondo Escribanos, Subfondo: Notaria 1, Serie: Dotes, Subserie: Cartas de Dote, Tomo: 28, Folios: 24v-25v, 20 de Agosto de 1754.
} 
Sudrot ${ }^{40}$ con un valor de 16 patacones, y finalmente el sombrero negro con punta cuyo valor fueron 20 patacones perteneciente a doña Petronila de la Pedroza ${ }^{41}$.

Existen dos sombreros de vicuña provenientes de los altiplanos andinos con un valor de 5 patacones entregado Francisca Quintero ${ }^{42}$, y doña Manuela Lozano $^{43}$. El poco valor de estos objetos, además del reducido monto de las dotes en los cuales se entregaron 648 patacones en el caso de Francisca Quintero y 865 patacones con 2 reales de doña Manuela Lozano, lleva a pensar que se trata de prendas poco valoradas, seguramente debido a la calidad del material usado para su confección o por tratarse de prendas que habían dejado de estar a la moda, o incluso por estar relacionadas a temas étnicos.

Por su parte los sombreros de Pelo de Castor eran altamente valorados, entre 20 y 18 patacones por pieza, aunque poco frecuentes ya que solo se encuentran dos registros. Finalmente, los sombreros podían mejorarse considerablemente como el perteneciente a la hija del rico comerciante don Gaspar de Soto y Zorrilla. Se trataba de "un sombrero negro guarnecido de plata punta de plata y oro y toquilla de oro" valorado en 20 patacones.

Hasta este punto es posible ver distintas geografías presentes en la cultura de consumo caleña. Por un lado, los textiles más finos y delicados destinados a la alcoba provenían de los centros de elaboración francesa, especializados en este tipo de producción y de alcance global. Los textiles más burdos, provenían en un gran número de Castilla y servían para el uso cotidiano, principalmente eran utilizados en la confección de mantillas, camisas y otras prendas.

Existe un textil que llama profundamente la atención como lo es el terciopelo, a pesar de su alto costo, no solo se restringía a casacas y sayas. La oferta de esta tela les permitió a las caleñas lucir prendas con una gran variedad de colores y formas. Finalmente, como complemento, incluían en sus atuendos hilos de oro y plata, bordados, y otros tejidos destinados a guarnecer sus prendas.

\section{La joyería como marcador de distinción, piedras preciosas de diversas latitudes}

Las joyas han sido un símbolo de poder dentro de la sociedad, elevando a quienes las usan a una categoría superior, envistiéndolas de estatus y

\footnotetext{
${ }^{40}$ AHC, Fondo Escribanos, Subfondo: Notaria 1, Serie: Dotes, Subserie: Cartas de Dote, Tomo: 29, Folios: 192-195, 8 de Junio de 1755.

${ }^{41}$ AHC, Fondo Escribanos, Subfondo: Notaria 1, Serie: Dotes, Subserie: Cartas de Dote, Tomo: 35, Folios: 14V-17, 18 de Enero de 1759.

${ }^{42}$ AHC, Fondo Escribanos, Subfondo: Notaria 1, Serie: Dotes, Subserie: Cartas de Dote, Tomo: 32, Folios: 61-63, 23 de Mayo de 1757.

${ }^{43}$ AHC, Fondo Escribanos, Subfondo: Notaria 1, Serie: Dotes, Subserie: Cartas de Dote, Tomo: 28, Folios: 160-162, 21 de Marzo de 1755.
} 
permitiéndoles hacer gala de la posición ocupada. Las mujeres de la ciudad de Santiago de Cali acompañaron sus vestimentas con un variado número de joyas. Zarcillos, brazaletes, orejeras, cadenas, rosarios, ahogadores, sortijas y otras piezas elaboradas en oro, sirvieron como marcador de distinción, además de en muchos casos ser una inversión fácilmente vendible en caso de necesidad. Otros materiales menos comunes fueron el coral, la Tumbaga y en menor medida la plata. Esta última fue usada principalmente para la fabricación de marcos labrados y algunos objetos de uso doméstico como platos, cucharas, jarrones y vasos.

En los registros era frecuente la presencia de incrustaciones de piedras preciosas, en la mayoría de los casos se trataba de esmeraldas y perlas, pero también aparecen amatistas, granates, corales, "piedras de Ynga" y diamantes. Estos minerales se articulaban al igual que los textiles a redes mercantiles y de circulación que iban más allá del ámbito local, vinculándose con las minas del interior del virreinato en el caso de las esmeraldas y al caribe a través de las perlas, solo por mencionar dos ejemplos. De las 26 cartas de dote, 22 contienen piezas de joyería dejando de aparecer solamente en 4 casos. Estos artículos registrados suman entre todos 314 patacones de a ocho reales.

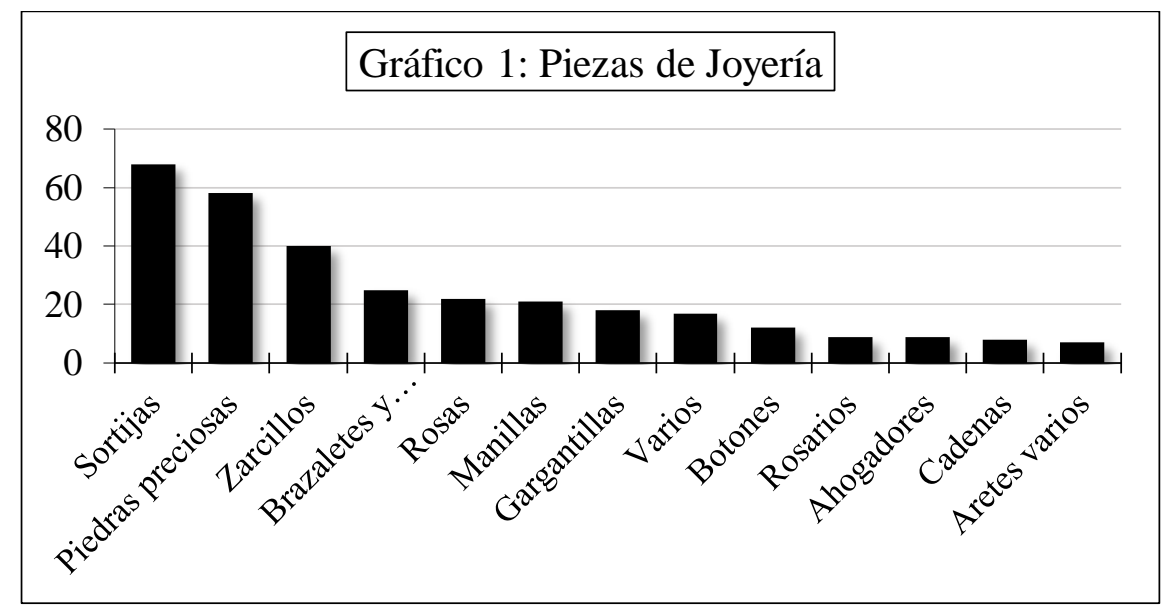

Fuente: elaborado por el autor con base en los registros notariales de cartas de dote consignados en el AHC, Fondo escribanos, Subfondo: Notaria Primera, Serie Dotes, Subserie: Cartas de Dote Tomos del 25 al 35, años de 1750-1759.

Las sortijas en su mayoría contaban con incrustaciones de esmeraldas además en su totalidad estaban fundidas en oro. La carta con el mayor número es la de Antonia de Castro y Zevallos ${ }^{44}$ con 7 registros, seguida por María Francisca de Soto y Zorrilla ${ }^{45}$ la cual entregó 6 . Otra carta con una presencia importante es la de doña Custodia Bravo de León ${ }^{46}$ con 4 sortijas de esmeraldas estimadas

\footnotetext{
${ }^{44}$ AHC, Fondo Escribanos, Subfondo: Notaria 1, Serie: Dotes, Subserie: Cartas de Dote, Tomo: 27, Folios: 142v-147v, 1 de Agosto de 1753.

${ }^{45}$ AHC, Fondo Escribanos, Subfondo: Notaria 1, Serie: Dotes, Subserie: Cartas de Dote, Tomo: 28, Folios: 58v, 60-62, 8 de Octubre de 1754.

${ }^{46}$ AHC, Fondo Escribanos, Subfondo: Notaria 1, Serie: Dotes, Subserie: Cartas de Dote, Tomo: 33, Folios: 43v-45, 16 de Febrero de 1758.
} 
en 20 patacones. Un caso particular es la sortija de amatistas con esmeraldas entregada por Juana Garcés y $\mathrm{Saa}^{47}$ en su carta de dote la cual se valoró en 12 patacones que, si bien no se trata de un valor alto, se trata de un objeto único. En el caso de doña María de $\mathrm{Saa}^{48}$, hermana de Bárbara de Saa, mujer poseedora de una gran fortuna, se registraron 7 sortijas fabricadas en oro con incrustaciones de esmeraldas, amatistas y un diamante en cada una. Debido a que en la región no se explotaba esta piedra preciosa, es claro que provenían de lugares mucho más lejanos, lastimosamente los registros no hablan de la antigüedad de la pieza con lo cual se podría establecer si se trató de herencia familiar.

Los zarcillos eran uno de los objetos de uso cotidiano de las mujeres caleñas. Estos pequeños pendientes posiblemente las acompañaban en sus actividades diarias, diferenciándose de otro tipo de aretes mucho más elaborados y de mayor costo. En las cartas dotales se registraron un total de 40 artículos con un valor estimado de 1051 patacones con 4 reales. En la siguiente tabla se exponen los materiales más comunes utilizados a la hora de fabricar zarcillos.

Tabla 3: Material de Fabricación de los Zarcillos

\begin{tabular}{lcc}
\hline \multicolumn{1}{c}{ Material } & Cantidad & Valor en Patacones \\
\hline Perlas & 23 & 785 \\
\hline Esmeraldas & 10 & 161,4 \\
\hline Oro & 4 & 43 \\
\hline Otros & 3 & 62 \\
\hline Total & $\mathbf{4 0}$ & $\mathbf{1 0 5 1 , 4}$
\end{tabular}

Fuente: elaborada por el autor con base en los registros notariales de cartas de dote consignados en el AHC, Fondo escribanos, Subfondo: Notaria Primera, Serie Dotes, Subserie: Cartas de Dote Tomos del 25 al 35, años de 1750-1759.

Además de los zarcillos se utilizaban candongas, orejeras y aretes que ayudaban a las damas a mostrar sus capacidades económicas, sin dejar de lado que también es posible que se trate de una cuestión más del gusto femenino.

Tabla 4: Otros tipos de aretes registrados 1750-1759

\begin{tabular}{lcc}
\hline \multicolumn{1}{c}{ Objeto } & Cantidad & Valor en Patacones \\
\hline Candongas de Perlas & 1 & 16 \\
\hline Candongas con Esmeraldas pequeñas & 2 & 9 \\
\hline Candongas de Oro & 1 & 8 \\
\hline Orejeras de Perlas & 2 & 16 \\
\hline Aretes de Oro & 1 & 7 \\
\hline
\end{tabular}

Fuente: elaborada por el autor con base en los registros notariales de cartas de dote consignados en el AHC, Fondo escribanos, Subfondo: Notaria Primera, Serie Dotes, Subserie: Cartas de Dote Tomos del 25 al 35, años de 1750-1759.

${ }^{47}$ AHC, Fondo Escribanos, Subfondo: Notaria 1, Serie: Dotes, Subserie: Cartas de Dote, Tomo: 27, Folios: 95-99v, Fecha: 7 de Julio de 1753.

${ }^{48}$ AHC, Fondo Escribanos, Subfondo: Notaria 1, Serie: Dotes, Subserie: Cartas de Dote, Tomo: 25, Folios: 134-137, 19 de Octubre de 1751. 
Los rosarios en la mayoría de los casos fabricados en oro eran también piezas comunes y de gran importancia no solo en la práctica cotidiana, sino también simbólica. Estos objetos acompañaban a sus dueñas en distintos espacios y momentos, tanto públicos como privados. Existen 9 rosarios con valores bastante diversos debido a la presencia de agregados como corales o a la calidad del Paternóster ${ }^{49}$ con que iban decorados. Si bien durante este decenio su presencia no es muy común y en general son objetos costosos, con el paso de los años y tal vez debido a un aumento por el culto mariano estas piezas experimentaran un creciente uso por parte de las mujeres de la ciudad. En la siguiente tabla se muestran los materiales de fabricación de los distintos rosarios, la cantidad de registros y su valor en patacones.

Tabla 5: Rosarios y Material de Fabricación 1750-1759

\begin{tabular}{lrr}
\hline \multicolumn{1}{c}{ Material } & Cantidad & Valor en Patacones \\
\hline Coral con cuentas de oro & 2 & 9 \\
\hline Coral & 1 & 20 \\
\hline Venturina azul engastado en oro & 1 & 28 \\
\hline Coco con Cruz y engalane de oro & 1 & 34 \\
\hline Oro & 1 & 40 \\
\hline Oro & 1 & 47 \\
\hline Oro & 1 & 88,6 \\
\hline Oro y óvalos & 1 & 125 \\
\hline
\end{tabular}

Fuente: elaborada por el autor con base en los registros notariales de cartas de dote consignados en el AHC, Fondo escribanos, Subfondo: Notaria Primera, Serie Dotes, Subserie: Cartas de Dote Tomos del 25 al 35, años de 1750-1759.

Las piedras preciosas entregadas de forma suelta fueron muy frecuentes durante este decenio. Entre ellas, 15 onzas de corales, 12 onzas de Granates ${ }^{50}$ 27 esmeraldas repartidas en dos cartas de dote, la María Francisca de Soto y Zorrilla $^{51}$ y la de doña María Gertrudis de Varona ${ }^{52}$.

En cuanto a los óvalos se registraron un total de 4 objetos con un valor de 11 patacones, lo cual los convierte en objetos un poco más frecuentes que las esmeraldas, normalmente se encontraban engastados en oro y acompañaban a las cadenas, pero en estos casos fueron dados por separado.

Existen una serie de objetos poco frecuentes, joyas que no estaban en poder de varias señoras y que con el paso de los años se harán populares o más comunes en las cartas dotales, otras por su parte simplemente desaparecerán de ellas.

\footnotetext{
${ }^{49}$ Esta es la frase con la cual inicia el padrenuestro, en este caso está refiriéndose al cristo que adorna el rosario

${ }^{50}$ Mineral formado por un compuesto de hierro, aluminio y silicio cuyo color más frecuente es el rojo oscuro ampliamente utilizado en la joyería en el mundo ibérico

${ }^{51}$ AHC, Fondo Escribanos, Subfondo: Notaria 1, Serie: Dotes, Subserie: Cartas de Dote, Tomo: 28, Folios: 58v, 60-62, 8 de Octubre de 1754.

${ }^{52}$ AHC, Fondo Escribanos, Subfondo: Notaria 1, Serie: Dotes, Subserie: Cartas de Dote, Tomo: 35, Folios: 99-100v, 2 de Abril de 1759.
} 
Tabla 6: Piezas de joyería poco frecuentes 1750-1759

\begin{tabular}{lrr}
\hline \multicolumn{1}{c}{ Pieza } & Cantidad & $\begin{array}{c}\text { Valor en } \\
\text { Patacones }\end{array}$ \\
\hline Ataguero de plata & 1 & 1 \\
\hline Cintillo de Perlas & 1 & 8 \\
\hline Cruz de Esmeraldas & 1 & 8 \\
\hline Cruz de esmeraldas y zarcillos de oro & 2 & 300 \\
\hline Hilos de Perlas & 2 & 90 \\
\hline Madeja de 16 hilos de perlas y Cruz de esmeraldas & 1 & 120 \\
\hline Madeja de perlas y esmeraldas & 1 & 45 \\
\hline Madeja de perlas y oro con cruz de esmeraldas & 1 & 26 \\
\hline Prendedores de oro & 2 & 6 \\
\hline Sartal con imagen & 1 & 14 \\
\hline Sartal de oro & 1 & 25 \\
\hline Sartal de oro con cruz de esmeraldas y estampa \\
guarnecida
\end{tabular}

Fuente: elaborada por el autor con base en los registros notariales de cartas de dote consignados en el AHC, Fondo escribanos, Subfondo: Notaria Primera, Serie Dotes, Subserie: Cartas de Dote Tomos del 25 al 35, años de 1750-1759.

Si bien la joyería tiene la particularidad de ser heredada además de funcionar como una inversión, es claro que las cantidades registradas no pueden corresponder únicamente a una acumulación hereditaria. La diversidad en los materiales nuevamente habla de conexiones comerciales, en el caso de las esmeraldas y perlas fácilmente identificables y cercanas. Por el contrario, diamantes y amatistas solo dan pistas sobre su procedencia.

Como marcador de estatus, forma de inversión, y finalmente accesorio indispensable, la joyería de la ciudad contiene un microcosmos de conexiones que van desde la procedencia de las piezas, pasando por la fabricación para llegar finalmente a su uso y atesoramiento.

\section{El mobiliario de una familia caleña, algunas aproximaciones a la cultura material de la ciudad}

Los distintos tipos de muebles y otros objetos decorativos son capaces de reflejar el nivel social de la familia, además de manifestar de forma directa el estilo de vida, las capacidades adquisitivas, y los gustos personales de sus propietarios. Estas piezas no solo dejan ver cuestiones de tipo económico, sino también cultural, el ritmo de vida y los hábitos domésticos de los miembros de la familia ${ }^{53}$.

\footnotetext{
${ }^{53}$ Oswaldo Callo, "Literatura y cultura material: El mobiliario doméstico en Lima (1840-1870)", en Scarlett O'phelan y Carlos Aguirre (eds.), Familia y vida cotidiana en América Latina siglos XVIII-XIX, Lima, Pontificia Universidad Católica del Perú, 2003, pp. 50-70.
} 
El mobiliario doméstico permite ver como las familias de la elite caleña decoraron y llenaron los distintos espacios de sus viviendas. Entre los objetos relacionados con la alcoba es posible encontrar: camas, colchones, almohadas, baúles y cajas de ropa entre otros. Para la cocina se entregaban pocillos, pailas, ollas frascos, platos, copas, y escudillas; los cuales fueron fabricados con una gran variedad de materiales y distintas procedencias. Para otros espacios como la sala, recibidores y posiblemente salones se entregaban sofás, sillas, sillones, mesas y los infaltables estrados.

En total se contabilizan 531 muebles y objetos relacionados con el uso doméstico con un valor de 5.525 patacones con 6 reales. De ellos, 109 registros son artículos de cocina, 36 son objetos relacionados con la habitación, 22 son herramientas para el trabajo agrícola y finalmente 226 están relacionados con la decoración de los espacios domésticos, entre ellos hay marcos de plata y algunas imágenes religiosas.

Gráfico 2: Cantidad Porcentual de las Distintas Categorías de Muebles

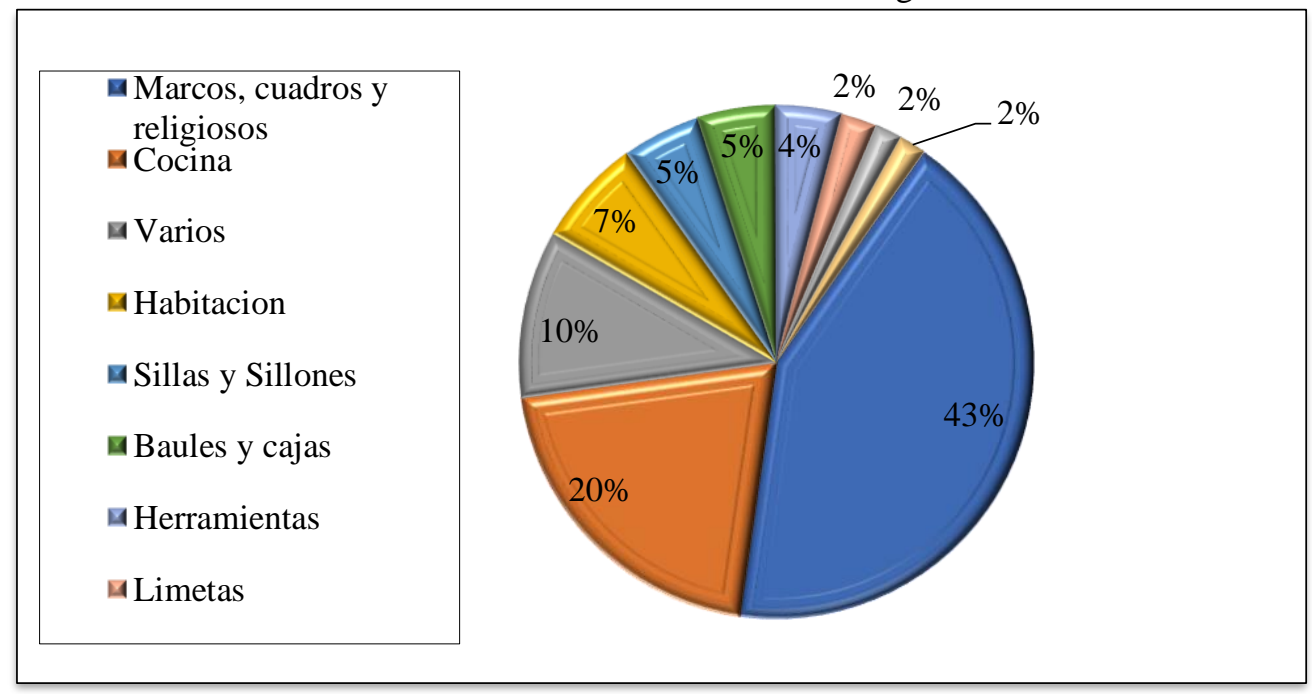

Fuente: elaborado por el autor con base en los registros notariales de cartas de dote consignados en el AHC, Fondo escribanos, Subfondo: Notaria Primera, Serie Dotes, Subserie: Cartas de Dote Tomos del 25 al 35, años de 1750-1759

Es necesario mencionar que el lecho matrimonial era símbolo de la vida en pareja que los recién casados se disponían a iniciar ${ }^{54}$. Por tanto uno de los muebles más importante dentro de la alcoba debía ser la cama. Se entregaron en total 5 piezas con un valor de 359 patacones y 4 reales, de estas, la más costosa se tasó en 200 patacones y le perteneció a Doña María Gertrudis de Varona $^{55}$. Si bien en este documento no se dan los detalles del mueble, su elevado valor hace pensar en la calidad que tenía. En promedio el valor de las

\footnotetext{
${ }^{54}$ O. Callo, "Literatura y cultura material: El mobiliario doméstico en Lima (1840-1870)", pp. 50-70

${ }^{55}$ AHC, Fondo Escribanos, Subfondo: Notaria 1, Serie: Dotes, Subserie: Cartas de Dote, Tomo: 35, Folios: 99-100v, 2 de Abril de 1759
} 
otras camas registradas está entre los 40 y los 50 patacones, siendo los dos ejemplos anteriores las de mayor valor.

Se entregaron en total 109 objetos relacionados con la cocina, entre los más frecuentes están: platos, vasos, ollas. La dote de doña María de Saa ${ }^{56}$ contiene algunos objetos interesantes, en este documento aparecen 5 Escudillas de China tazadas en 10 patacones y 3 escudillas de Talavera ${ }^{57}$ adicionalmente, doña María aportó 14 Platos de la mayoría ambas procedencias con un valor de 8 reales. Los vasos por su parte son muy poco frecuentes, solo 2 cartas dotales contienen este tipo de elemento. Nuevamente aparecen en la dote de doña María de Saa, con 5 vasos de cristal con un valor de 40 patacones y 8 vasos de China tasados en 8 patacones. El otro registro es el de 7 vasos entregados por Juana Garcés y Saa ${ }^{58}$ en 6 patacones, de los cuales no se tiene mayor información.

Con el paso de los años, los diversos objetos provenientes de "Oriente" aumentarían su presencia en el mercado local. Lastimosamente la documentación no deja claro si la circulación de estos se daba por vía de contrabando o si por el contrario su recorrido se había realizado por vía "legal". El carácter de las piezas da cuenta de objetos utilitarios más que propiamente lujosos, esto no es de extrañar debido al tipo de producción chino, principalmente orientado a la manufactura de bajo costo, buena calidad y grandes volúmenes ${ }^{59}$.

En este caso particular, los registros hablan de vasos y platos principalmente, sin embargo, era también frecuente el uso de pequeñas cajas lacadas, lastimosamente no se especifica su origen en las cartas de dote. Es necesario explorar con mayor detalle la presencia de bienes asiáticos en este territorio, la seda utilizada para la elaboración de prendas de vestir podría ampliar aún más el panorama, si bien podría pensarse que se trata de una particularidad, o en su defecto de las posibilidades económicas de la familia Saa, es necesario vincular estos vienes con perspectivas históricas mucho mayores, en las cuales la conexión entre China y las Indias ha sido ya establecida y explorada.

Como ya se ha mencionado anteriormente los cuadros y objetos religiosos estaban dentro de la cotidianidad familiar, la concepción católica del mundo vinculaba objetos, espacios y prácticas de consumo ${ }^{60}$. Esto objetos artísticos eran europeos, quiteños o santafereños, sin descartar la posibilidad de un

\footnotetext{
${ }^{56}$ AHC, Fondo Escribanos, Subfondo: Notaria 1, Serie: Dotes, Subserie: Cartas de Dote, Tomo: 25 Folios: 134-137, 19de Octubre de 1751

${ }^{57}$ Una escudilla es un tipo de recipiente de forma semiesférica, ancho, no muy grande ni muy hondo y sin asas ni labio, usado individualmente para comer con cuchara y beber sorbiendo. Esta pieza alfarera fue un objeto de uso básico en el servicio de mesa desde la edad media hasta mediados del siglo XX.

${ }^{58}$ AHC, Fondo Escribanos, Subfondo: Notaria 1, Serie: Dotes, Subserie: Cartas de Dote, Tomo: 27, Folios: $95-99 v$, 7 de Julio de 1753.

${ }^{59}$ Mariano Bonialian, China en la América Colonial. Bienes, mercados, comercio y cultura del consume desde México hasta Buenos Aires, Buenos Aires, Editorial Biblos, 2014.

${ }^{60}$ Edgardo Pérez Morales, "Vida material, religiosidad y sociedad colonial. Espacios, objetos y prácticas de consumo en el colegio jesuita de la ciudad de Antioquia". Revista Historia Critica, 38, 2008: 70-95.
} 
origen local. En las cartas se registraron 5 artículos con carácter religioso durante esta primera década y su número irá en aumento con el paso de los años. Entre ellos podemos encontrar los siguientes:

- Señor San Juan en 12 patacones $^{61}$

- Cuadro de la Santísima Trinidad en 8 patacones ${ }^{62}$

- Santo Cristo valorado en 3 patacones ${ }^{63}$

- 2 Crucifijos de madera con engastes de oro cada uno en 6 patacones ${ }^{64}$

- 14 Cuadros religiosos cada uno en 4 patacones ${ }^{65}$.

Estos solo han sido algunos de los bienes que componían la materialidad de una casa caleña vista a través de las cartas de dote. Exponer la diversidad de objetos que componían la cultura material resultaría demasiado extenso y complejo, debido a variables como los gustos personales, las capacidades económicas además de la actividad productiva desarrollada por la familia de la novia. Sin embargo, es posible hacerse una idea general no solo de las posibilidades de las élites de la ciudad, sino también de la disponibilidad de determinados objetos.

Las mujeres ingresaban por vía de dote diversos objetos, su familia se aseguraba de aprovisionarlas de objetos para la cocina, entre ellos, platos y vasos de diversa índole. Entre el mobiliario se encuentran elementos como la cama matrimonial, sillas de distinto tipo, mesas, escritorios, baúles y sofás elaborados en madera y con distintos agregados. Igualmente, frecuentes son el dinero en efectivo o el oro en polvo, así como esclavos, inmuebles, y un sinfín de pequeños objetos personales que sorprenden en ocasiones por su lujo, por lo particulares o finalmente por su simplicidad.

\section{Conclusiones}

Este texto buscó realizar un corto acercamiento a algunos objetos que componían la vida material de la ciudad de Cali, vista a través de las cartas de dote. Las mujeres pertenecientes a familias prestantes de la ciudad invirtieron grandes sumas de dinero para asegurar una buena dote, entre otras cosas buscando asegurar un matrimonio ventajoso con un patrimonio inicial en muchos casos más que satisfactorio. Es por esto que este "patrimonio inicial" iba compuesto por la mayor cantidad y variedad de enseres posible: ropa, joyería, mobiliario, dinero, animales y en algunos casos esclavos e inmuebles, permitían asegurar un patrimonio familiar sólido.

\footnotetext{
${ }^{61}$ AHC, Fondo Escribanos, Subfondo: Notaria 1, Serie: Dotes, Subserie: Cartas de Dote, Tomo: 27 Folios: 95-99v, 7 de Julio de 1753.

${ }^{62}$ AHC, Fondo Escribanos, Subfondo: Notaria 1, Serie: Dotes, Subserie: Cartas de Dote, Tomo: 27 Folios: 142v-147v, 1 de Agosto de 1753.

${ }^{63}$ AHC, Fondo Escribanos, Subfondo: Notaria 1, Serie: Dotes, Subserie: Cartas de Dote, Tomo: 32 Folios: 26v-28, 20 de Abril de 1757.

${ }^{64}$ AHC, Fondo Escribanos, Subfondo: Notaria 1, Serie: Dotes, Subserie: Cartas de Dote, Tomo: 29, Folios: 192-195, 8 de Junio de 1755.

${ }^{65}$ AHC, Fondo Escribanos, Subfondo: Notaria 1, Serie: Dotes, Subserie: Cartas de Dote, Tomo: 27, Folios: 95-99v, 7 de Julio de 1753.
} 
En cuanto a la procedencia de los objetos, la existencia de redes comerciales garantizó la existencia de una oferta diversa tanto de materiales como de adornos. Los valores son sumamente diversos y responden a la calidad y representatividad del material usado, haciendo profundamente complicado establecer tendencias de precios. Sin embargo, es posible establecer geografías del consumo presentes en la cultura material de la ciudad. Por un lado, los textiles más finos provenían del norte de Francia y se destinaban a las alcobas, aquellos de uso cotidiano y de menor valor llegan a la ciudad desde España, o centros textiles cercanos. Para las vestimentas más elaboradas era frecuente el uso de materiales como el terciopelo y el tafetán, cuya fabricación no era local.

La joyería habla de otras conexiones, principalmente ligadas al caribe, el altiplano cundiboyacense, la península ibérica y otros espacios sobre los cuales solo se puede especular, especialmente con respecto a los diamantes. La presencia de estas joyas con las incrustaciones de piedras finas que poseen la gran mayoría, son imposibles de imaginar en una sociedad que se cree tenía una vida material y económica pobre. Su registro por el contrario nos habla de unos sectores acomodados con excedentes económicos, y quienes seguramente invirtieron en estos objetos no solo como medio para exteriorizar su posición social, a manera de inversión para una posible emergencia económica.

Es necesario considerar también el oficio de joyero sin el cual la presencia de todas estas piezas se hace impensable, pero del cual no se tienen mayores registros ni menciones, quedan preguntas sin resolver como: ¿De dónde provenían las joyas? ¿Fueron fabricadas en la ciudad? ¿Quiénes eran los encargados de complacer a una señora cuando esta requería de nuevas alhajas? Sumado a ello, las grandes distancias recorridas por estos objetos, la cantidad de agentes comerciales implicados y la logística en el transporte son elementos sobre los cuales debe profundizarse, si bien se trataba de una ciudad ubicada en una zona aparentemente marginal en el contexto imperial hispánico, su rica cultura material y de consumo, habla de un espacio bien conectado.

Los objetos de uso cotidiano provenientes de oriente, su bajo costo, además de adaptabilidad y calidad habían ganado un espacio en el mundo indiano y no es de extrañar que tuviesen presencia en la ciudad. La práctica de adquirir objetos traídos del extranjero se ve con mayor claridad en aquellos utensilios destinados al consumo de los alimentos: platos, vasos, ollas y otros tantos provenían de lugares tan lejanos como China, pero también llegaban de España.

Como conclusión se puede afirmar que la vinculación cada vez mayor y más efectiva de la ciudad a los mencionados circuitos comerciales tanto transatlánticos como transpacíficos les permitió a sus sectores de elite y es 
posible especular que también a otros sectores menos favorecidos, acceder a mercancías europeas, asiáticas y de otros virreinatos. Cada una de las piezas entregadas en las cartas de dote nos está dando cuenta de algún tipo de red de circulación ya sea local, regional, o global en las que el contrabando impulsado por las actividades mineras propias de la ciudad y la incapacidad de la metrópoli para satisfacer las necesidades de mercancías de calidad propias de la población se hacían visibles.

Sumado a ello, se debe tener presente siempre la situación geopolítica de la segunda mitad del siglo XVIII, la paz con Francia, la guerra con Inglaterra, las nuevas políticas comerciales impulsadas por la dinastía borbónica, pueden tener sus ecos en la presencia o no de mercaderías en la ciudad. Sumado a ello, la producción de oro y el contrabando también cumplieron un papel central en la consolidación de una cultura del consumo tendiente a las prendas de calidad y la suntuosidad.

\section{Bibliografía}

\section{Fuentes Primarias}

Archivo Histórico de Cali. Fondo escribanos, Subfondo: Notaria Primera, Serie Dotes, Subserie: Cartas de Dote Tomos del 25 al 35, años de 1750-1760.

Las siete partidas del Rey Don Alfonso el Sabio, cotejadas con varios códices antiguos por la Real Academia de la Historia. Tomo tercero. Disponible en: http://www.cervantesvirtual.com/obra-visor/las-siete-partidas-del-rey-don-alfonsoel-sabio-cotejadas-con-varios-codices-antiguos-por-la-real-academia-de-la-historiatomo-3-partida-quarta-quinta-sexta-y-septima--0/html/01fb8a30-82b2-11df-acc7$\underline{002185 \text { ce6064_92.htm }}$

\section{Fuentes Secundarias}

Braudel, Fernand, Civilización material y capitalismo, Barcelona, Editorial Labor S. A., 1974.

Bonialian, Mariano, China en la América Colonial. Bienes, mercados, comercio y cultura del consume desde México hasta Buenos Aires, Buenos Aires, Editorial Biblos, 2014.

Callo, Oswaldo, "Literatura y cultura material: El mobiliario doméstico en Lima (18401870)" en Scarlett O'phelan y Carlos Aguirre, Familia y vida cotidiana en América Latina siglos XVIII-XIX, Lima, Pontificia Universidad Católica del Perú, 2003.

Colmenares, Germán, Cali: terratenientes, mineros y comerciantes. Siglo XVIII, Cali, Universidad del Valle, 1976.

Chocano Mena, Magdalena, La América Colonial (1492-1763), Madrid, Editorial Síntesis, 2000.

Flynn, Dennis O. and Giraldez, Arturo, "Bom with a Silver Spoon: The Origin of World Trade in 1571", Journal of World History, 6, (2), 1995: 201-221. 
Gamboa, Jorge. El precio de un Marido: El significado de la dote matrimonial en el Nuevo Reino de Granada. Pamplona (1550-1650). Bogotá, Instituto Colombiano de Antropología e Historia, Colección Cuadernos Coloniales, 2003.

Gauderman, Kimberly, Women's Lives in Colonial Quito: Gender, Law and Economy in Spanish America, Austin, University of Texas Press, 2009.

Gonzalbo Aizpuru, Pilar, "De la penuria y el lujo en la Nueva España: Siglos XVIXVIII". Revista de Indias, 56, (206), 1996: 49-77.

Gunder Frank, Andre, Reorient, Global Economy in Asian Age, Berkeley, University of California Press, 1998.

Marichal, Carlos, "El peso de la plata hispanoamericana como moneda universal del antiguo régimen (siglo XVI a XVIII)", en Carlos Marichal, Steven Topik y Zephyr Frank (coords.), De la Plata a la Cocaína. Cinco siglos de historia económica de América Latina, 1500-,2000, México, FCE/El Colegio de México, 2017.

Martínez Carreño Aída, La prisión del vestido: Aspectos sociales del traje en América. Bogotá, Planeta Editorial, 1995.

Mair Lucy, Matrimonio, Barcelona, Barral Editores 1972.

Pérez Morales, Edgardo. "Del hábitat a los hábitos. Vida material y sociedades urbanas en el Nuevo Reino de Granada, siglo XVIII" en, Yobenj Aucardo ChicanganaBayona. Ed. Historia, cultura y sociedad colonial, siglos XVI-XVIII. Temas, problemas y perspectivas, Medellín, La Carreta, Universidad Nacional de Colombia, 2008.

Pérez Morales, Edgardo, "Vida material, religiosidad y sociedad colonial. Espacios, objetos y prácticas de consumo en el colegio jesuita de la ciudad de Antioquia". Historia Critica, 38, 2008: 70-95.

Perrot, Michelle, Historia de las alcobas, Madrid, Siruela, 2011.

Quintero Toro, Camilo, "Entendiendo los objetos y las mercancías en perspectiva histórica: presentación del dossier 'Objetos y mercancías en la historia". Historia Critica, 38, 2009.

Rodríguez, Pablo, Sentimientos y vida familiar en el Nuevo Reino de Granada, Bogotá, Editorial Planeta, 1997.

Rodríguez Sánchez, Ángel, "Un modelo metodológico: las cartas de dote en Extremadura”. Jornadas de Metodología Histórica Aplicada. La documentación Notarial y la Historia, Vol. I, Santiago de Compostela; 1984.

Squicciarino, Nicola, El vestido habla: Consideraciones psicosociológicas sobre la indumentaria, Madrid, Ediciones Cátedra, 1990.

Yun, Bartolomé, "Cultural material: consumo, niveles de vida, estilo de vida”. Noticiario de Historia Agraria, 6, 1993: 139-142. 